\title{
Experimental Research on Compression Properties of Cement Asphalt Mortar due to Drying and Wetting Cycle
}

\author{
Ping Wang, Hao Xu, Rong Chen, Jingmang Xu, and Xiaohui Zeng \\ MOE Key Laboratory of High-Speed, Railway Engineering, Southwest Jiaotong University, Chengdu 610031, China \\ Correspondence should be addressed to Hao Xu; xhao0@163.com
}

Received 10 July 2014; Accepted 18 November 2014; Published 14 December 2014

Academic Editor: Krystyn Van Vliet

Copyright (C) 2014 Ping Wang et al. This is an open access article distributed under the Creative Commons Attribution License, which permits unrestricted use, distribution, and reproduction in any medium, provided the original work is properly cited.

\begin{abstract}
Uniaxial compression test of cement asphalt (CA) mortar specimens, due to drying and wetting cycle of $0,2,4$ and 8 times, is carried out by using the electronic universal test machine, with the strain rate ranging from $1 \times 10^{-5} \mathrm{~s}^{-1}$ to $1 \times 10^{-2} \mathrm{~s}^{-1}$. The effects of strain rate and drying and wetting cycle time on the compressive strength, elasticity modulus, and stress-strain full curve are investigated. Experimental results show that the strain-stress full curve of CA mortar is affected obviously by strain rate and drying and wetting cycle time. The compressive strength and elasticity modulus increase with the strain rate under the same drying and wetting cycle time. The compressive strength and elasticity modulus decrease with the increase of drying and wetting cycle time in the same strain rate. The lower the strain rate is, the greater the compressive strength and elasticity modulus of CA mortar decrease. When the strain rate is $1 \times 10^{-5} \mathrm{~s}^{-1}$ and drying and wetting cycle time is 8 , the largest reduction of average compressive strength of CA mortar is $40.48 \%$, and the largest reduction of elasticity modulus of CA mortar is $35.51 \%$, and the influence of drying and wetting cycle on the compressive strength of CA mortar is greater than its influence on the elasticity modulus.
\end{abstract}

\section{Introduction}

Slab ballastless track is a track structure, which is widely used in high speed railway (HSR). The cement emulsified asphalt mortar (CA mortar) layer as a filling layer between track slab and concrete supporting layer functions in support, load transfer, adjustment, reduction, and isolate vibration [15]. The long-term service performance of CA mortar is very important in the regularity and durability of track and the safety and comfort of the vehicle driving $[6,7]$.

As the buffer, damping structure layer of slab ballastless track, CA mortar is mainly under the vertical load and in dynamic loading process $[8,9]$, so the influence of loading rate on the mechanical properties of CA mortar was researched in paper [10-13]. Wang et al. [10] explored the variation in compressive strength of CA mortar under different loading rates. Kong et al. [11] tested the compressive stress-strain of two CAMs at different displacement rates ranging from $0.3 \mathrm{~mm} / \mathrm{min}$ to $30 \mathrm{~mm} / \mathrm{min}$. And the correlation between peak strength or elastic modulus and loading rates was acquired. Yongliang et al. [12] tested two typical CAMs at varied deformation rates over a range of
0.3 to $30 \mathrm{~mm} / \mathrm{min}$ at room temperature, and the correlation between the mechanical properties and temperature or loading rates was acquired. Xie et al. [13] studied the single-axis compressive characteristic of CRTS I type slab tracks CA mortar under different strain rates. CA mortar is vulnerable in natural environmental conditions chronically under its service process. The rain and sun cycles will have a negative impact on the mechanical properties of CA mortar inevitably, but the variation law on mechanical properties of CA mortar under the drying and wetting cycle has not been reported in China or abroad. In this paper, the writer studied the deterioration laws of mechanical properties of CA mortar, using specimen of CA mortar made in laboratory on the basis of the drying and wetting cycle experiment, which can provide an experimental basis for the deterioration mechanism of CA mortar.

\section{Experimental}

2.1. Raw Materials. Cement emulsified asphalt mortar special dry ingredients are mainly mixed with cement, sand, 
TABLE 1: Properties of emulsified asphalts.

\begin{tabular}{|c|c|c|c|c|}
\hline Number & Item & Unit & Requesting & Value \\
\hline 1 & Engler viscosity $\left(25^{\circ} \mathrm{C}\right)$ & & $5 \sim 15$ & 8.0 \\
\hline 2 & Ratioof screen residue $(1.18 \mathrm{~mm})$ & $\%$ & $<0.1$ & 0 \\
\hline 3 & Storage stability $\left(1 \mathrm{~d}, 25^{\circ} \mathrm{C}\right)$ & $\%$ & $<1.0$ & 0.3 \\
\hline 4 & Storage stability $\left(5 \mathrm{~d}, 25^{\circ} \mathrm{C}\right)$ & $\%$ & $<5.0$ & 3.2 \\
\hline 5 & Residue of mixing with cement & $\%$ & $<1.0$ & 0.3 \\
\hline 6 & \multirow{4}{*}{$\begin{array}{c}\text { Needle penetration }\left(25^{\circ} \mathrm{C}, 100 \mathrm{~g}\right) \\
\text { Solubility (trichloroethylene) } \\
\text { Ductility }\left(5^{\circ} \mathrm{C}\right) \\
\text { Ductility }\left(15^{\circ} \mathrm{C}\right)\end{array}$} & $0.1 \mathrm{~mm}$ & $60 \sim 120$ & 78.5 \\
\hline 7 & & $\%$ & $>97$ & 98.0 \\
\hline 8 & & $\mathrm{~cm}$ & $\geqslant 20$ & 26.5 \\
\hline 9 & & $\mathrm{~cm}$ & $\geqslant 50$ & 61.2 \\
\hline
\end{tabular}

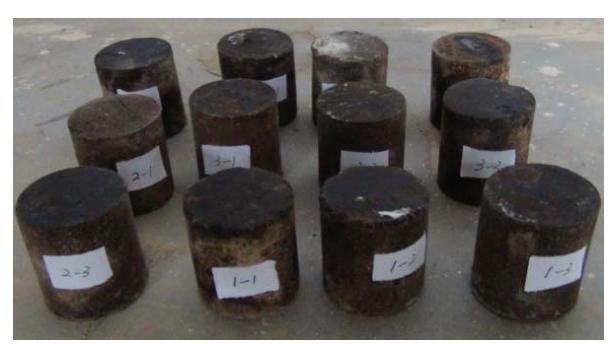

(a) Standard specimen of CA mortar

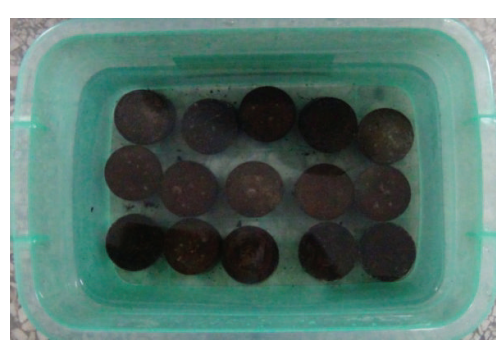

(b) CA mortar specimens immersed in water

FIgURE 1: CA mortar specimens.

and other additives. Its basic mixture ratio is cement: sand: expanders $=1: 2: 0.1$. Pure Portland cement with a strength grade of 42.5 , complying with the Chinese National Standard GB175-1999, was used. The $24 \mathrm{~h}$ volume expansion rate of this cement emulsified asphalt mortar special dry ingredients is $2.1 \%$, whose $7 \mathrm{~d}$ line expansion rate is $0.1 \%$ and the 1-day compressive strength is $6.89 \mathrm{MPa}$.

The asphalt emulsion is the special emulsified asphalt of CA mortar on CRTS I type slab ballastless track, whose solid mass fraction is $62.1 \%$. And the viscosity, penetration, and ductility of asphalt emulsion can meet the requirements of the temporary technology criterion of cement and emulsified asphalt mortar in CRTS (China railway track system) I type slab track of passenger dedicated railway, whose main properties are listed in Table 1.

The J-funnel flow time of fresh CA mortar is $24 \mathrm{~s}$, and the resolution is $0.2 \%$. The mix proportion of CA mortar is $\mathrm{m}$ (dry ingredients) $: \mathrm{m}$ (asphalt) $: \mathrm{m}$ (water $)=1100: 515: 50$. Mixing water is the tap water.

2.2. Sample Preparation. According to the given mixture of CA mortar, put the emulsified asphalt and water into the pot and stir slowly, and add the dry ingredients into the spot slowly in the slowly stir condition. After the dry ingredients were added, stir rapidly for $3 \mathrm{~min}$ and then stir for $1 \mathrm{~min}$. The fluidity, apparent density, gas content, and other properties of fresh CA mortar were measured according to the method in [10]. The fluidity of CA mortar was $24 \mathrm{~s}$. The apparent density was $1610 \mathrm{~kg} \cdot \mathrm{m}^{-3}$ and the gas content was $8.2 \%$. Then fresh
CA mortar was placed into cylindrical plastics moulds with size $\Phi 50 \mathrm{~mm} \times 50 \mathrm{~mm}$, forming 90 specimens. After being cured in the constant temperature $(23 \pm 2)^{\circ} \mathrm{C}$ and constant humidity $(65 \pm 5) \%$ for 24 hours, the samples were removed from the moulds, transferred into the standard room, and cured for 120 days, and then we did the drying and wetting cycle experiment and compression test.

2.3. Testing Method. In order to simulate the condition of CA mortar layer under drying and wetting cycle, CA mortar specimens were immersed in water for 7 days and then put them in outdoor for natural withering 7 days. The environment temperature was kept at $20^{\circ} \mathrm{C}$, and the drying and wetting cycle times were $0,2,4$, and 8 . And then, at the regulation age, the mechanical property of CA mortar specimens was tested. The CA mortar specimens and the specimens which were immersed in water were given in Figure 1.

The mechanical property test of CA mortar, uniaxial compressive test of CA mortar specimens in different immersion time, was carried out by using the universal electronic test machine (Figure 2) according to the method in paper [6], keeping the environment temperature at $20^{\circ} \mathrm{C}$ when testing. Considering the loading ability of the experimental system, loading rates of $0.03 \mathrm{~mm} / \mathrm{min}, 0.3 \mathrm{~mm} / \mathrm{min}, 3 \mathrm{~mm} / \mathrm{min}$, and $30 \mathrm{~mm} / \mathrm{min}$ were set for testing the CA mortar specimens. Strain rates were $1 \times 10^{-5} \mathrm{~s}^{-1}, 1 \times 10^{-4} \mathrm{~s}^{-1}, 1 \times 10^{-3} \mathrm{~s}^{-1}$, and $1 \times 10^{-2} \mathrm{~s}^{-1}$, which were obtained according to the size of CA mortar specimens, taking $1 \times 10^{-5} \mathrm{~s}^{-1}$ as a quasistatic 


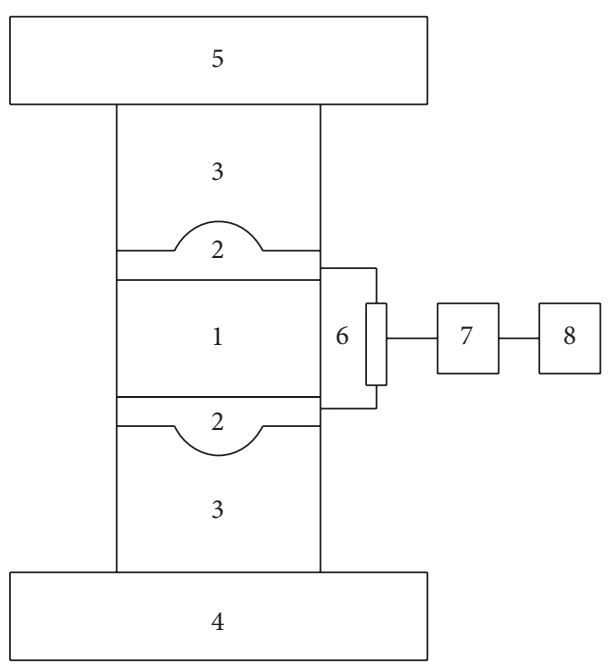
(1) Test specimen
(5) Servosystem
(2) The hinge of loading head
(6) Displacement sensor
(3) Loading member bar
(7) Signal conversion equipment
(4) Load transducer
(8) Data collection system

FIGURE 2: The schematic of universal testing machine in the loading direction.

strain rate. Two loading surfaces were coated with French chalk to reduce the surface restraint effect and three samples were used for each test as duplication. If the test results are discrete, the number of specimens should be increased in order to ensure the validity of test data. Specimens should be preloaded three times with loading rate of $0.5 \mathrm{~mm} / \mathrm{min}$ and strength of $0.05 \mathrm{MPa}$ before the formal loading in order to prevent the error because of the surface unevenness of CA mortar samples.

\section{Results and Discussion}

3.1. Stress-Strain Curve of CA Mortar. The mechanical property of CA mortar was fully reflected by the stress-strain full curve of CA mortar. The stress-strain full curves of CA mortar of CRTS I slab ballastless track are shown in Figure 3. Figure 3(a) shows the stress-strain full curves of CA mortar under different strain rates, without drying and wetting cycle. As shown in Figure 3(a), the stress-strain curves of CA mortar change obviously under different strain rates, and the ultimate compressive strength of CA mortar increases with the strain rate. Figure 3(b) shows the stress-strain full curves of CA mortar under different drying and wetting cycle times when the strain rate is $1 \times 10^{-4} \mathrm{~s}^{-1}$. As shown in Figure 3(b), the ultimate compressive strength of CA mortar decreases with the increase of drying and wetting cycle time. The strength of CA mortar decreases slowly when the strength of CA mortar reaches the peak strength. The existence of asphalt improves the fracture toughness of CA mortar, and the CA mortar still has enough bearing capacity when the strain reaches $10 \%$, which indicates that the CA mortar has good toughness and ductility.
TABLE 2: Compressive strengths of CA mortar under different drying and wetting cycle times.

\begin{tabular}{cccccc}
\hline \multirow{2}{*}{ Strain rates $/ \mathrm{s}^{-1}$} & \multirow{2}{*}{ Test } & \multicolumn{4}{c}{ Compressive strength/MPa } \\
& & 0 times & 2 times & 4 times & 8 times \\
\hline \multirow{3}{*}{$1 \times 10^{-5}$} & 1 & 3.301 & 2.872 & 2.051 & 1.915 \\
& 2 & 3.277 & 2.882 & 2.058 & 2.017 \\
& 3 & 3.367 & 2.981 & 2.129 & 1.987 \\
& Average & $\mathbf{3 . 3 1 5}$ & $\mathbf{2 . 9 1 2}$ & $\mathbf{2 . 0 7 9}$ & $\mathbf{1 . 9 7 3}$ \\
\hline \multirow{4}{*}{$1 \times 10^{-4}$} & 1 & 3.858 & 3.594 & 2.871 & 2.456 \\
& 2 & 3.781 & 3.448 & 2.764 & 2.537 \\
& 3 & 3.954 & 3.501 & 2.765 & 2.412 \\
& Average & 3.864 & 3.514 & $\mathbf{2 . 8 0 0}$ & $\mathbf{2 . 4 6 8}$ \\
\hline \multirow{4}{*}{$1 \times 10^{-3}$} & 1 & 5.283 & 4.285 & 3.684 & 3.299 \\
& 2 & 5.232 & 4.221 & 3.739 & 3.403 \\
& 3 & 5.192 & 4.084 & 3.619 & 3.255 \\
& Average & $\mathbf{5 . 2 3 5}$ & $\mathbf{4 . 1 9 6}$ & $\mathbf{3 . 6 8 0}$ & $\mathbf{3 . 3 1 9}$ \\
\hline \multirow{3}{*}{$1 \times 10^{-2}$} & 1 & 7.121 & 6.349 & 5.040 & 4.622 \\
& 2 & 7.184 & 6.261 & 4.903 & 4.508 \\
& 3 & 7.102 & 6.183 & 4.917 & 4.587 \\
& Average & $\mathbf{7 . 1 3 5}$ & $\mathbf{6 . 2 6 4}$ & $\mathbf{4 . 9 5 3}$ & $\mathbf{4 . 5 7 2}$ \\
\hline
\end{tabular}

3.2. Compressive Strength of CA Mortar. The uniaxial compressive strength of CA mortar under different drying and wetting cycle times and strain rates are shown in Table 2.

As shown in Table 2, the ultimate compressive strength increases with the strain rate under the same drying and wetting cycle time. After drying and wetting cycle for $0,2,4$, and 8 times, the average strength of CA mortar in the strain rates of $1 \times 10^{-4} \mathrm{~s}^{-1}, 1 \times 10^{-3} \mathrm{~s}^{-1}$, and $1 \times 10^{-2} \mathrm{~s}^{-1}$ increases by $16.56 \%, 20.67 \%, 34.68 \%$, and $25.09 \%, 57.92 \%, 44.09 \%, 77.01 \%$, and $68.22 \%$, and $115.23 \%, 115.11 \%, 138.24 \%$, and $131.72 \%$ comparing with that in the strain rate of $1 \times 10^{-5} \mathrm{~s}^{-1}$. The strength of CA mortar comes from the hydration of cement and demulsification of asphalt emulsion, and the skeleton structure of CA mortar is formed by the asphalt being coated with hydration product of cement and sand [14]. The strength of CA mortar is provided by the connection between cement hydration products and asphalt or connection between sand and asphalt. Damage of CA mortar is mainly caused by the internal crack of its skeleton. With the increase of strain rate, the microcrack of CA mortar could not extend timely, and the lateral inertia confinement effect of asphalt's network structure will prevent the development of microcrack, which results in the compressive strength improvement of CA mortar.

Influences of strain rate on the compressive strength of CA mortar under different drying and wetting cycle times are shown in Figure 4.

As shown in Table 2 and Figure 4, the ultimate compressive strength of CA mortar decreases with the increase of drying and wetting cycle time under the same strain rate. When the strain rates are $1 \times 10^{-5} \mathrm{~s}^{-1}, 1 \times 10^{-4} \mathrm{~s}^{-1}, 1 \times$ $10^{-3} \mathrm{~s}^{-1}$, and $1 \times 10^{-2} \mathrm{~s}^{-1}$, the drying and wetting cycle times are 2,4 , and 8 , and the average compressive strength of CA mortar decreases by $12.15 \%, 9.06 \%, 19.84 \%$, and $12.21 \%$, 


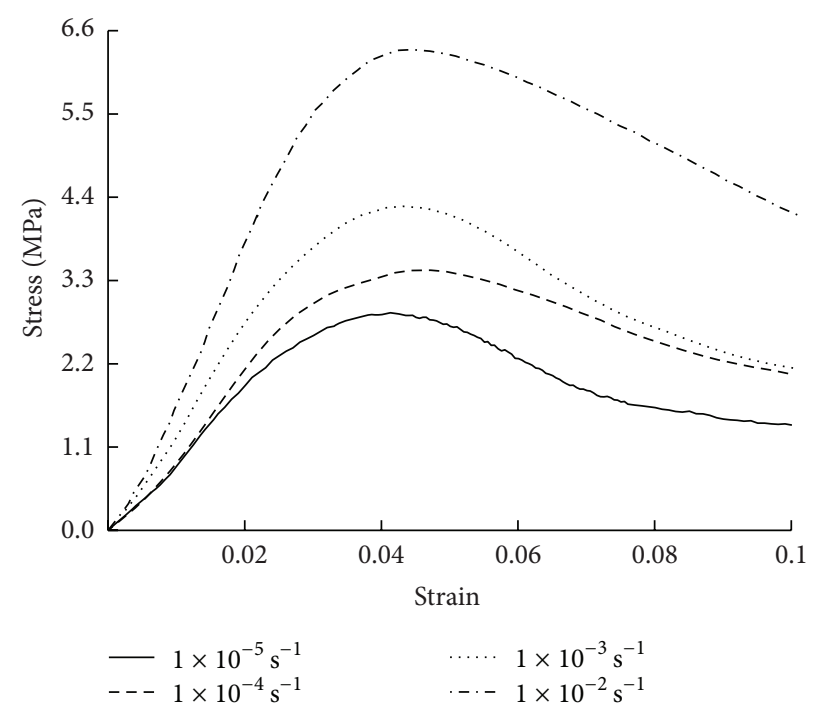

(a) Different strain rates

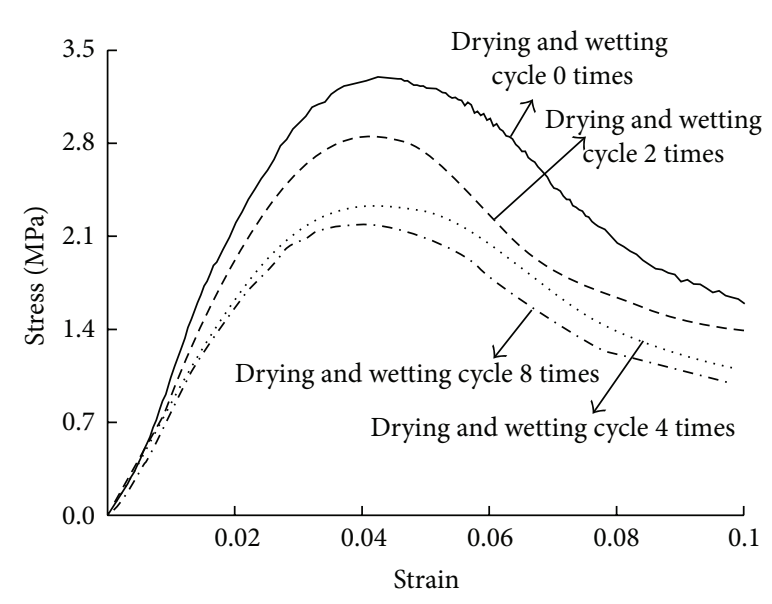

(b) Strain rate is $1 \times 10^{-4} \mathrm{~s}^{-1}$

FIGURE 3: Stress-strain full curves of CA mortar.

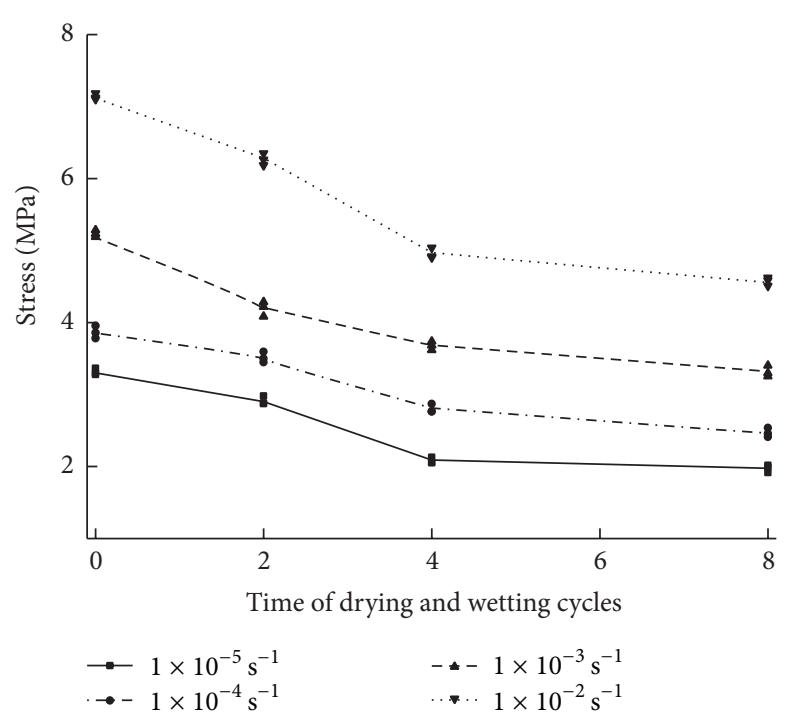

FIgURE 4: Compressive strength of CA mortar at different strain rates and drying and wetting cycle times.

$37.28 \%, 27.53 \%, 29.70 \%$, and $30.58 \%$, and $40.48 \%, 36.12 \%$, $36.59 \%$, and $35.92 \%$ compared with that without drying and wetting cycle. The stress generated by dry shrinkage and wet expansion deformation of CA mortar will damage the CA mortar with the developing of drying and wetting. The stress concentration zoon, which is formatted in the weak interfaces between network of asphalt and cement hydration products and between network structure and sand, results in micropore and cracks. The internal damage of CA mortar accumulates continually, and the strength of CA mortar reduces gradually. When the microcracks extend to a regular degree, the stress generated by dry shrinkage and wet expansion will decrease continuously. In the macroscopic level, the decrease of compressive strength of CA mortar trends to stability.

3.3. Relationship between Elasticity Modulus and Cycle Time. The elasticity modulus of materials reflects the recovery capacity of deformation; the higher the elasticity modulus, the stronger the recovery capacity of deformation. Use the secant modulus of compressive strength of $0 \sim 1 / 3$ as the elastic modulus of CA mortar [13], which is the following formula:

$$
E_{d}=\frac{\left(\sigma_{1 / 3}-\sigma_{0}\right)}{\left(\varepsilon_{1 / 3}-\varepsilon_{0}\right)},
$$

in which $E_{d}$ is the elasticity modulus of CA mortar and $\sigma_{1 / 3}$ is the $1 / 3$ of ultimate compressive strength. $\sigma_{0}$ is the initial stress. In this experiment, $\sigma_{0}$ is $0 . \varepsilon_{1 / 3}$ is the strain corresponding to $\sigma_{1 / 3} \cdot \varepsilon_{0}$ is the initial strain value, which is 0 . Through the analysis of stress-strain curve, the elasticity moduli of CA mortar at different drying and wetting cycle times are shown in Table 3.

Table 3 demonstrates that the elasticity modulus of CA mortar increases with the strain rate under the same drying and wetting cycle time. After drying and wetting cycle for $0,2,4$, and 8 times, the elasticity modulus of CA mortar in the strain rates of $1 \times 10^{-4} \mathrm{~s}^{-1}, 1 \times 10^{-3} \mathrm{~s}^{-1}$, and $1 \times 10^{-2} \mathrm{~s}^{-1}$ increases by $10.48 \%, 7.28 \%, 14.77 \%$, and $16.43 \%, 39.08 \%$, $34.30 \%, 51.95 \%$, and $47.88 \%$, and $87.87 \%, 88.94 \%, 102.76 \%$, and $102.02 \%$ compared with that in the strain rate of $1 \times$ $10^{-5} \mathrm{~s}^{-1}$. The elasticity modulus of CA mortar reflects the recovery capacity of deformation, so the sensibility of strain rate on the elasticity modulus of CA mortar can improve the stability of train driving.

Influences of strain rate on the average elastic modulus of CA mortar under different drying and wetting cycle times are shown in Figure 5. 
TABLE 3: Elasticity modulus of CA mortar under different drying and wetting cycle times.

\begin{tabular}{cccccc}
\hline \multirow{2}{*}{${\text { Strain rates } / \mathrm{s}^{-1}}^{*}$ Test } & \multicolumn{4}{c}{ Elastic modulus E/MPa } \\
& & 0 times & 2 times & 4 times & 8 times \\
\hline \multirow{3}{*}{$1 \times 10^{-5}$} & 1 & 88.400 & 72.509 & 65.867 & 56.372 \\
& 2 & 84.466 & 76.698 & 60.604 & 55.212 \\
& 3 & 79.382 & 84.585 & 54.641 & 51.005 \\
& Average & $\mathbf{8 4 . 0 8 2}$ & $\mathbf{7 7 . 9 3 1}$ & $\mathbf{6 0 . 3 7 0}$ & $\mathbf{5 4 . 1 9 6}$ \\
\hline \multirow{3}{*}{$1 \times 10^{-4}$} & 1 & 94.824 & 87.467 & 75.179 & 62.379 \\
& 2 & 88.195 & 85.362 & 61.631 & 59.477 \\
& 3 & 95.666 & 77.999 & 71.060 & 67.446 \\
& Average & $\mathbf{9 2 . 8 9 5}$ & $\mathbf{8 3 . 6 0 9}$ & $\mathbf{6 9 . 2 9 0}$ & $\mathbf{6 3 . 1 0 1}$ \\
\hline \multirow{3}{*}{$1 \times 10^{-3}$} & 1 & 124.793 & 109.343 & 90.576 & 80.792 \\
& 2 & 110.982 & 100.494 & 89.461 & 77.084 \\
& 3 & 115.053 & 104.158 & 95.169 & 82.562 \\
& Average & $\mathbf{1 1 6 . 9 4 2}$ & $\mathbf{1 0 4 . 6 6 4}$ & $\mathbf{9 1 . 7 3 6}$ & $\mathbf{8 0 . 1 4 6}$ \\
\hline \multirow{3}{*}{$1 \times 10^{-2}$} & 1 & 150.201 & 142.525 & 115.953 & 107.252 \\
& 2 & 162.436 & 152.803 & 123.504 & 107.602 \\
& 3 & 161.260 & 146.402 & 127.761 & 113.613 \\
& Average & $\mathbf{1 5 7 . 9 6 6}$ & $\mathbf{1 4 7 . 2 4 3}$ & $\mathbf{1 2 2 . 4 0 6}$ & $\mathbf{1 0 9 . 4 8 9}$ \\
\hline
\end{tabular}

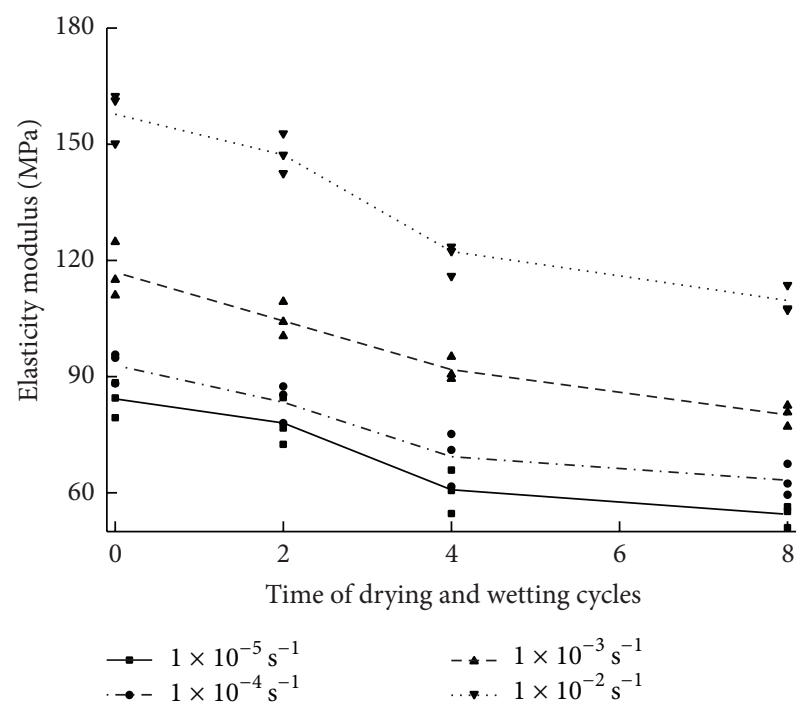

FIGURE 5: Elastic modulus of CA mortar.

As shown in Table 3 and Figure 5, elasticity modulus of CA mortar decreases with the increase of drying and wetting cycle time under the same strain rate. When the strain rates are $1 \times 10^{-5} \mathrm{~s}^{-1}, 1 \times 10^{-4} \mathrm{~s}^{-1}, 1 \times 10^{-3} \mathrm{~s}^{-1}$, and $1 \times 10^{-2} \mathrm{~s}^{-1}$, the drying and wetting cycle times are 2,4 , and 8 ; the average elastic modulus of CA mortar decreases by $7.31 \%, 9.99 \%$, $10.49 \%$, and $6.79 \%, 28.20 \%, 25.41 \%, 21.55 \%$, and $22.51 \%$, and $35.51 \%, 32.07 \%, 31.46 \%$, and $30.69 \%$ comparing with that without drying and wetting cycle. With the continuation of drying and wetting cycle, the internal structure of CA mortar will be damaged, the recovery capacity of deformation will be weakened, and the elasticity modulus of CA mortar decreases gradually. The reason is similar to the change of
CA mortar's compressive strength. The attenuation rate of elasticity modulus of CA mortar decreases slowly.

\section{Conclusions}

The stress-strain relationship of CA mortar under different strain rates and drying and wetting cycle times has been got through the uniaxial compression experiment, and the change rule of related mechanics index has also been analyzed. The following conclusions can be drawn.

(1) The mechanical property of CA mortar is influenced obviously by strain rates and drying and wetting cycle times.

(2) Because the stress generated by dry shrinkage and wet expansion deformation of CA mortar will damage the CA mortar, the compressive strength and elasticity modulus decrease with the increase of drying and wetting cycle times in the same strain rate. When the strain rate is $1 \times 10^{-5} \mathrm{~s}^{-1}$ and the drying and wetting cycle time is 8 , the largest reduction of average compressive strength of CA mortar is $40.48 \%$, and the largest reduction of elasticity modulus of CA mortar is $35.51 \%$.

(3) Under the same drying and wetting cycle time, since microcracks inside the CA mortar can not develop in time, the ultimate compressive strength and elastic modulus will increase with the strain rate. The maximum increase of compressive strength is $138.24 \%$, and the largest increase of elasticity modulus is $102.76 \%$.

(4) The influence of drying and wetting cycle on the compressive strength of CA mortar is greater than its impact on the elasticity modulus.

\section{Conflict of Interests}

The authors declare that there is no conflict of interests regarding the publication of this paper.

\section{Acknowledgments}

This research was supported by the National Science Foundation of China (51425804, 51208439, and U1234201), the National Basic Research Program of China (2013CB036202), and the Science and Technology Innovation Team of Sichuan Province (2011JTD0008).

\section{References}

[1] E. Coenraad, "Recent development in slab track," European Railway Review, vol. 9, no. 2, pp. 81-85, 2003.

[2] A. Katsuoshi, "Development of slab tracks for Hokuriku Shinkansen line," Quarterly Report of RTRI, vol. 42, no. 1, pp. 35-41, 2001.

[3] X. Zeng, Y. Xie, and D. Deng, "Conductivity behavior of the fresh CA mortar and its relationship with the fluidity properties," Construction and Building Materials, vol. 36, pp. 890-894, 2012. 
[4] X.-H. Zeng, Y.-J. Xie, D.-H. Deng, and G.-C. Long, "Vibration adsorption and separation capacities of CA mortar," Journal of Building Materials, vol. 16, no. 2, pp. 345-348, 2013 (Chinese).

[5] H. Xu, P. Wang, and X. H. Zeng, "Present research situation and prospect of CA mortar used in slab ballastless track of highspeed railway," Railway Standard Design, no. 11, pp. 1-5, 2013 (Chinese).

[6] D. Tian, D. Deng, Q. Tian, Y. Pan, and S. Tang, "Effect of water on dynamic mechanical properties of cement emulsified asphalt mortar," Journal of the Chinese Ceramic Society, vol. 41, no. 11, pp. 1507-1513, 2013 (Chinese).

[7] D. Tian, Q. Yuan, R. Zhu, C. Wang, and D. Deng, "Effect of water on static mechanical properties of cement emulsified asphalt mortar," Journal of the Chinese Ceramic Society, vol. 40, no. 11, pp. 1544-1552, 2012 (Chinese).

[8] P. R. Zhao and X. Y. Liu, "Analysis on dynamic performance for slab track and its parameter research," Railway Engineering, no. 5, 2004 (Chinese).

[9] C.-B. Cai, W.-M. Zhai, and K.-Y. Wang, "Dynamics simulation of interactions between high-speed train and slab track laid on bridge," China Railway Science, vol. 25, no. 5, pp. 57-60, 2004 (Chinese).

[10] F.-Z. Wang, Z.-C. Liu, and S.-G. Hu, "Influence of loading rate on compressive strength of CA mortar," Journal of Beijing University of Technology, vol. 34, no. 10, pp. 1059-1065, 2008 (Chinese).

[11] X.-M. Kong, Y.-L. Liu, and P.-Y. Yan, "Influence of loading rate on mechanical properties of cement asphalt mortars," Journal of Building Materials, vol. 13, no. 2, pp. 187-192, 2010 (Chinese).

[12] L. Yongliang, K. Xiangming, Z. Yanrong, and Y. Peiyu, "Static and dynamic mechanical properties of cement-asphalt composites," Journal of Materials in Civil Engineering, vol. 25, no. 10, pp. 1489-1497, 2013.

[13] Y.-J. Xie, X.-H. Zeng, D.-H. Deng, B.-J. Liu, and K.-R. Zheng, "Mechanical characteristics of China railway track system (CRTS) I type slab tracks CA mortar under different strain rates," Journal of Building Materials, vol. 13, no. 4, pp. 483-528, 2010 (Chinese).

[14] Q. Wang, A. Ru-han, and P. Y. Yan, "Influence of $\mathrm{m}(\mathrm{S}) / \mathrm{m}(\mathrm{C})$ and sand gradation on compressive strength and fluidity of CA mortar," Journal of Railway Science and Engineering, vol. 5, no. 6, pp. 1-5, 2008 (Chinese). 

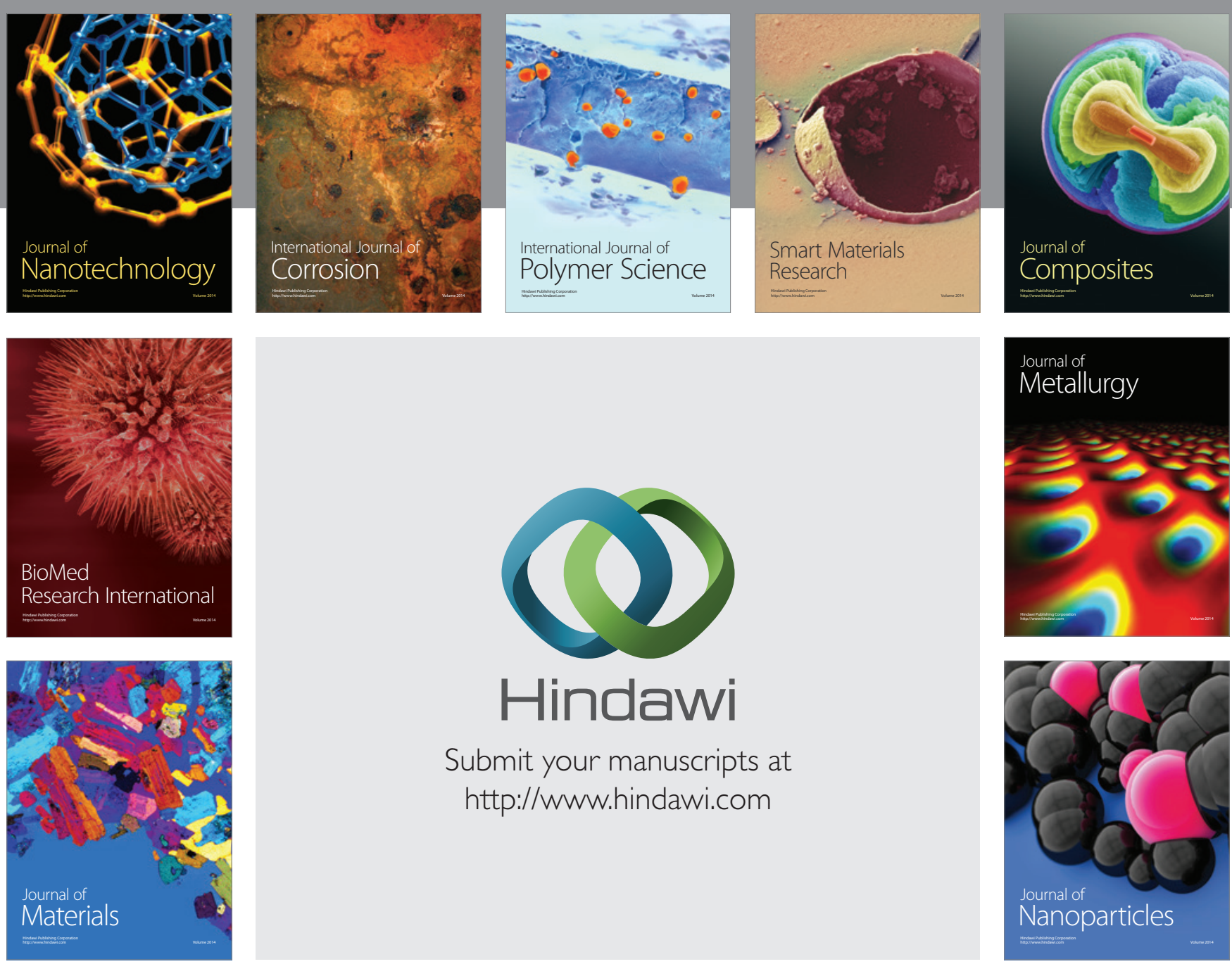

Submit your manuscripts at http://www.hindawi.com
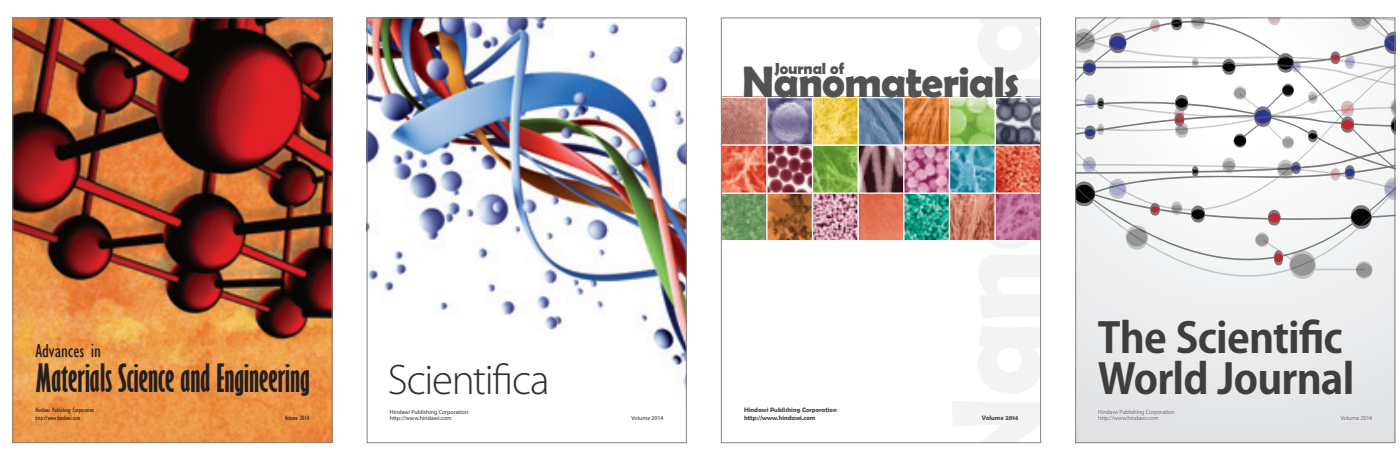

\section{The Scientific World Journal}
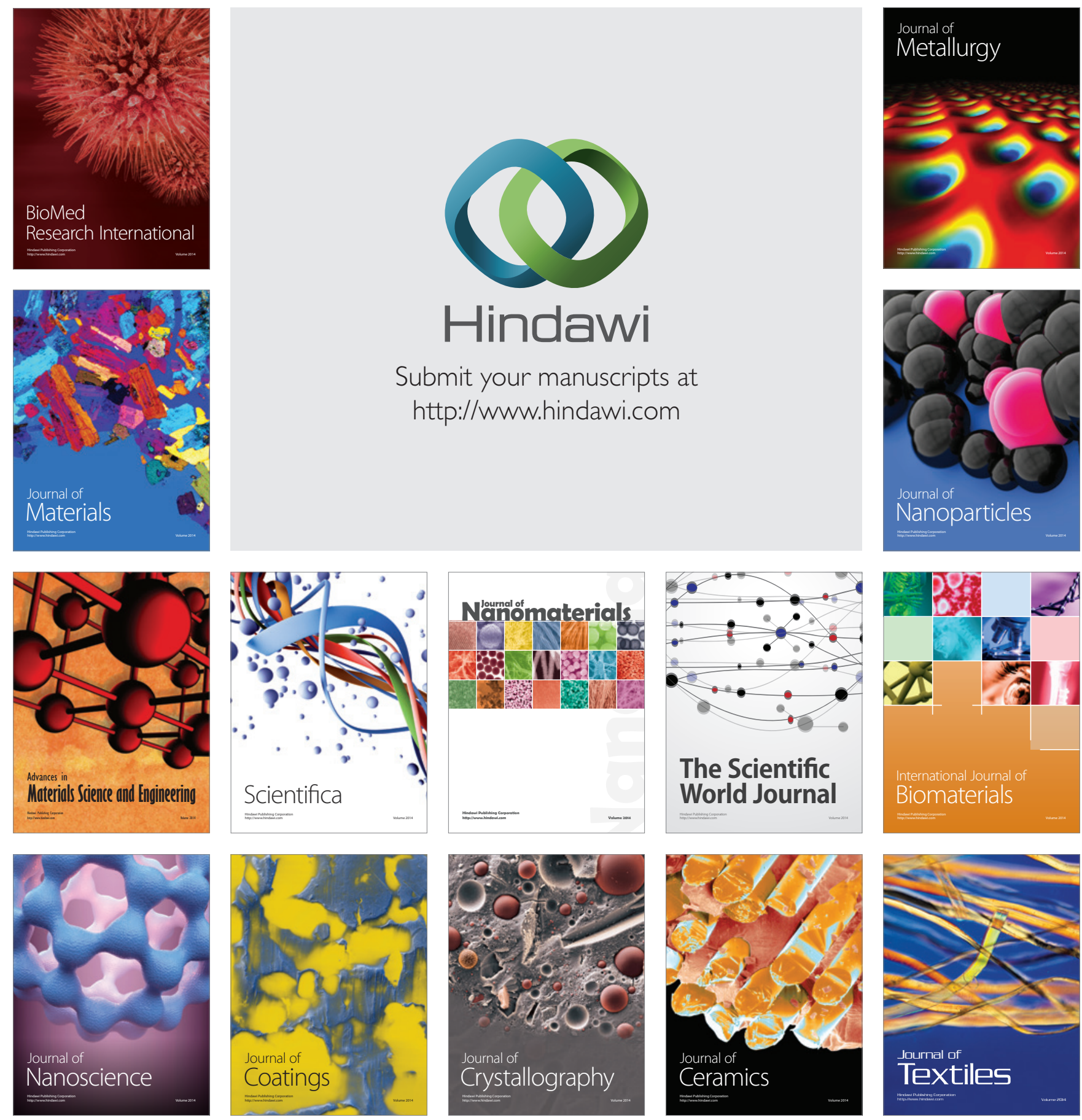